Foro Interno. Anuario de Teoría Política

ISSN: 1578-4576

http://dx.doi.org/10.5209/FOIN.57203

\title{
De lo alto en lo bajo: Carl Schmitt y la representación teológico-política de los valores
}

\author{
Franco Castorina ${ }^{1}$
}

Recibido: 21 de febrero de 2016 / Aceptado: 9 de septiembre de 2016

Resumen: Si la teología política es uno de los temas centrales que recorre la obra de Carl Schmitt, el problema de los valores - a pesar de los pocos trabajos dedicados al tema - no deja de tener importancia en relación con las reflexiones de este autor. El propósito de este trabajo es, precisamente, mostrar el vínculo existente entre uno y otro, entre la teología política schmittiana y su reflexión en torno a los valores. Para ello, nos proponemos recorrer, por una parte, sus textos tempranos, que nos permitirán dilucidar la relación entre teología y política en la modernidad y, por otro lado, la crítica a la filosofía de los valores elaborada en La tiranía de los valores. A partir de ese recorrido bifurcado intentaremos trazar la continuidad existente entre la teología política y los valores que, a nuestro juicio, puede rastrearse ya en El valor del Estado y el significado del individuo.

Palabras clave: Teología política; valores; Schmitt; catolicismo; protestantismo; representación.

\section{[en] From Top to Bottom: Carl Schmitt and the Theological-political Rep- resentation of Values}

\begin{abstract}
If political theology is one of the central themes running through the work of Carl Schmitt, the problem of values - in spite of the few studies devoted to the subject - is a significant matter in Schmitt's thinking. In consequence, the purpose of this paper is to show the link between the two, namely between Carl Schmitt's political theology and his reflections on values. To this end, his early texts are examined here, which will allow us to elucidate the relationship between theology and politics within modernity and then to critique the philosophy of values developed in The Tyranny of Values. From that forked path, the continuity which exists between political theology and values will be analysed and found to be located to a large extent in The Value of the State and the Significance of the Individual.

Keywords: Political theology; values; Schmitt; Catholicism; Protestantism; representation.
\end{abstract}

Cómo citar: Franco Castorina, "De lo alto en lo bajo: Carl Schmitt y la representación teológicopolítica de los valores”: Foro Interno. Anuario de Teoría Política, vol. 17 (2017), pp. 15-33.

\section{Introducción: la raíz teológico-política de la modernidad}

Uno de los conceptos que ha signado la interpretación cabal del pensamiento filosófico-político moderno ha sido la noción de secularización. Si bien no es posible agotar este concepto en una definición, desde una lectura tradicional se ha comprendido

\footnotetext{
1 Instituto Gino Germani, Facultad de Ciencias Sociales, Universidad de Buenos Aires (Argentina)

E-mail: fpcastorina@hotmail.com
} 
como un proceso que lleva a término la separación entre los diversos dominios concretos del pensamiento y de la acción humana; esto es, como un desarrollo que escinde, finalmente, lo moral, lo político, lo religioso y lo económico como esferas presuntamente autónomas y autofundantes. Según este esquema, y en virtud de otra interpretación también tradicional, se ha leído la obra de Niccolò Machiavelli (14691527) — aunque desde una perspectiva filosófico-política o teórico-política- como aquella que inaugura este modo de pensar la política como esfera autónoma separada de la moral y de la religión, inscribiendo su pensamiento en el linaje de los grandes fundadores. Ahora bien, sabemos gracias a Leo Strauss (1899-1973) que esta separación entre esferas autónomas, entre dominios específicos del pensamiento, entre "provincias de la cultura", es tan solo una premisa liberal'.

Es en este marco donde la lectura schmittiana de la secularización ingresa para denunciar el desplazamiento operado por el liberalismo. En este sentido, la ya eximia fórmula de Carl Schmitt (1888-1985) que da inicio al capítulo III de su obra Teología política. Cuatro capítulos sobre la doctrina de la soberanía (1922) puede ilustrar su comprensión: "Todos los conceptos centrales de la moderna teoría del Estado son conceptos teológicos secularizados"3. La crítica al liberalismo — gesto schmittiano par excellence- consiste en minar la presunta autonomía y autofundamentación de la modernidad, develando que la génesis de los conceptos jurídicopolíticos modernos tienen su raíz en una secularización de los conceptos teológicos ${ }^{4}$. De acuerdo con esta lectura sutil de la modernidad, el liberalismo no solo es incapaz de concretar la imposible separación entre la religión y la política, sino que su propio modo de pensar se deriva de la Reforma, es decir, de la teología protestante que, como veremos más adelante, al separar a Dios del mundo, propicia un viraje hacia el individuo como soporte fundamental para el desarrollo de la racionalidad formal

2 Cf. Leo Strauss, "Comentario sobre El concepto de lo político, de Carl Schmitt", en Heinrich Meier, Carl Schmitt, Leo Strauss y El concepto de lo político. Sobre un diálogo entre ausentes, Katz, Buenos Aires, 2008, pp. 133-168.

3 Carl Schmitt, Teología política, Trotta, Madrid, 2009, p. 37.

4 La referencia al liberalismo como blanco de la crítica de Schmitt aparece matizada por Leo Strauss, cuando en el último párrafo del "Comentario sobre El concepto de lo político, de Carl Schmitt" referenciado en la nota 2, señala que: "Ya hemos dicho (en A 14) que Schmitt emprendía la crítica del liberalismo en un mundo liberal; y con ello queríamos decir que su crítica del liberalismo se desarrolla en el horizonte del liberalismo; que su tendencia antiliberal permanece contenida por la 'sistemática del pensamiento liberal', que 'aún no ha sido reemplazada por ningún otro sistema’. La crítica al liberalismo sólo podrá consumarse si se logra conquistar un horizonte más allá del liberalismo". Citado en Meier, Carl Schmitt, Leo Strauss y El concepto de lo político, p. 168. Si bien esta indicación es plausible sobre todo teniendo como marco de referencia el hecho de que Schmitt subraya la autonomía y especificidad de lo político respecto de otras esferas como la estética, la moral o la religión, esto no significa que lo político se halle en la práctica librado de toda referencia moral, estética o religiosa. En efecto, para Schmitt, los motivos de una guerra no pueden ser evaluados bajo la óptica de lo bueno o lo malo, de lo bello o lo feo, sino desde la distinción entre amigo y enemigo. Ahora bien, la lógica amigo-enemigo se vuelve efectiva en la medida en que una comunidad política ponga en riesgo la forma de vida de otra comunidad política. Véase Carl Schmitt, El concepto de lo político, en Héctor Orestes Aguilar, Carl Schmitt, teólogo de la política, Fondo de Cultura Económica, México, D.F., 2001, pp. 169-223. La pregunta que se impone ante esta afirmación es de qué modo se configuran esas formas de vida que permiten la convivencia humana al interior de un territorio, forma que podemos denominar de modo muy general "comunidad" (Gemeinschaft en alemán), concepto que abre toda una serie interminable de debates que no podemos tratar aquí. Con esto no pretendemos desacreditar la crítica de Strauss a Schmitt, sino, simplemente, sostener que la noción de lo político, y la distinción específica sobre la que se asienta, conviven tanto en la práctica como en la teoría con nociones propias de la teología de las que no pueden desprenderse totalmente (tal como se evidencia en los textos "teológico-políticos" de Schmitt que vamos a reponer). 
técnico-instrumental, inherente al "espíritu capitalista"5. Por otra parte, tampoco son casuales las constantes referencias y guiños del Jurist al pensamiento jurídico-político de Thomas Hobbes (1588-1679). Para Carl Schmitt, el modo en el que el pensador inglés conceptualiza el Estado tiene firmes reverberaciones cristianas, de raigambre católica. Para ser más claros, de acuerdo a la particular lectura schmittiana del Leviatán de Hobbes, la autoridad estatal es una forma jurídico-política secularizada de la autoridad católica fundamental, la Iglesia, cuya tarea consiste en representar - mediante la persona del Papa, como vicario de Cristo - el reino de lo trascendente en lo inmanente ${ }^{6}$.

La encarnación de Dios en Cristo establece un vínculo completamente opuesto al anidado por el protestantismo respecto a la relación entre Dios y mundo. Si para el protestantismo, Dios y mundo se hallan separados o, lo que es lo mismo, gracia y naturaleza se encuentran desgarrados, la redención humana individual es imposible y nada de este mundo puede garantizarnos la salvación. Para el catolicismo, en cambio, la encarnación de Dios en el cuerpo de Cristo implica la posibilidad de visibilizar lo invisible, esto es, de representar lo trascendente en lo inmanente mediante la mediación institucional de la Iglesia. En este sentido, podría decirse que el problema fundamental que informa la diferencia entre catolicismo y protestantismo no gira en torno al contenido, sino en torno al acceso a Dios.

Este prolegómeno orienta el sentido de nuestra indagación sobre el problema de los valores en la obra de Carl Schmitt. Si bien, a primera vista, los valores no parecen ser una cuestión central en la obra de este autor, creemos que este tema aparece recurrentemente en sus escritos juveniles y tempranos, aunque posiblemente solapado entre las vastas y más célebres reflexiones que plantea en torno a otros conceptos como la soberanía y el Estado, entre otros. En cualquier caso, este tópico aparece explícitamente tematizado en un texto tardío de su obra titulado La tiranía de los valores (1979), en donde Schmitt recupera e indaga la filosofía de los valores iniciada en el contexto alemán de fines del siglo diecinueve y principios del siglo veinte y elabora, en virtud de su interpretación de tal movimiento, una crítica a esa forma de concebir la axiología. Sin adelantar demasiado, creemos que la crítica que Schmitt realiza en esta obra se apoya en el modo en el que esa filosofía de los valores se vincula con la religión. Para poder establecer este vínculo entre el valor (ético-político) y la religión, es preciso suponer que la relación que se establece entre el individuo y el valor es del orden de la creencia. De esta manera, podemos trazar una continuidad formal entre la relación individuo-valor e individuo-Dios, postulando que las formas de pensar la ligazón entre el individuo y su acceso a Dios se prolongan en diversas formas de pensar el nexo entre el individuo y su Idea de lo justo.

En suma, en este trabajo pretendemos dilucidar el modo en el cual el individuo se relaciona con los valores en la obra de Carl Schmitt, tomando en consideración el vínculo que el Jurist establece entre los valores y la religión católica, anclado en

5 Esta ascendencia protestante del liberalismo ya es recuperada por Max Weber (1864-1920) en su célebre y clásico escrito La ética protestante y el espíritu del capitalismo (1905), en donde se constata que la racionalidad técnico-instrumental que informa la modernidad capitalista tiene como punto de referencia el desencantamiento o desmagificación operado por las modulaciones protestantes en torno al cristianismo. Véase Max Weber, $L a$ ética protestante y el espíritu del capitalismo, Alianza, Madrid, 2011.

6 Esta idea de una representación de lo trascendente en lo inmanente - y que alude a la metáfora espacial de la representación de "lo alto" en "lo bajo" - será desarrollada más adelante en el apartado dedicado al concepto de representación teológico-político. 
el concepto fundamental de representación teológico-política, de raíz cristológica. Para ello, proponemos restituir, precisamente, este concepto de representación teológico-política que se desprende de los tempranos textos schmittianos y de aquellos de la década de 1920 que, asimismo, serán los que nos provean la cifra hermenéutica para comprender la crítica a la filosofía de los valores emprendida en La tiranía de los valores. Por último, como contrapartida a esta crítica a la axiología alemana, propondremos otro modo de comprender el vínculo entre el individuo y los valores, ya implícito en un texto juvenil de Schmitt, titulado El valor del Estado y el significado del individuo (1914); nexo, creemos, de orden teológico-político.

Una lectura cercana al texto, como la que aquí se propone, está motivada por el programa straussiano que propone elaborar una historia no historicista de la filosofía política ${ }^{7}$; esto es, seguir una estrategia de lectura que presupone que, para poder llevar a término una crítica de la doctrina y enseñanza de un gran pensador, es necesario previamente intentar comprenderla tan bien como la comprendió su autor. En vista de esta estrategia, la restitución del argumento de Schmitt se circunscribe al esfuerzo de comprensión, en el convencimiento de que solo tras un esfuerzo de este tipo estarán dadas las condiciones para un ecuánime distanciamiento crítico. Caso contrario, se corre el riesgo de quedar a mitad de camino entre la doctrina del pensador y nuestros prejuicios acerca de ella. Por ello, solo una vez presentados los argumentos de Schmitt, desglosados en tres apartados, estaremos en condiciones de pasar a la crítica.

\section{La representación teológico-política}

No es posible precisar y desarrollar el concepto de representación teológico-política que se deriva de la obra del jurista alemán, sin antes recuperar la lectura de la teología cristiana - eminentemente católica- que el propio Schmitt elabora en dos textos sumamente relevantes para nuestra indagación: La visibilidad de la Iglesia. Una reflexión escolástica, publicado en la revista católica Summa en 1917, y Catolicismo romano y forma política, publicado en 1923. Estos textos nos permitirán comprender el modo en el cual el catolicismo comprende la relación existente entre Dios, el hombre y el mundo y su franca oposición a la teología protestante respecto de estas mismas relaciones.

La reflexión católico-romana de Schmitt sobre la visibilidad de la Iglesia se inaugura identificando dos tesis. Una primera tesis sostiene que el hombre no se encuentra en soledad en el mundo; la segunda, asimismo, indica que el mundo es bueno, puesto que es anterior al pecado, cuyo origen radica en el hombre. Agrega Schmitt que "ambas ideas adquieren significado religioso porque Dios se hizo hombre". La encarnación divina en Cristo, el Mediador, es el fundamento que sostiene ambas tesis. La venida de Cristo al mundo supone que Dios y el hombre se hallan vinculados mediante su institución, su Iglesia. Si Dios se hizo hombre mediante un cuerpo mundano, la Iglesia también cobra existencia encarnándose en un cuerpo mundano.

Véase Leo Strauss y Joseph Cropsey, Historia de la filosofía politica, Fondo de Cultura Económica, México, D. F., 2004.

8 Carl Schmitt, "La visibilidad de la Iglesia. Una reflexión escolástica", trad. Román García Pastor: Daimon. Revista de Filosofia, n. ${ }^{\circ} 13$ (1996), p. 11. 
Esto significa que si bien Dios y la Iglesia son ajenos a este mundo, no dejan de pertenecer a él al visibilizarse. Es en virtud de esta jerarquía de las mediaciones y de la comprensión de que el mundo es bueno porque antecede al pecado, que se puede colegir que lo visible y lo mundano tengan como fundamento y origen lo invisible y lo divino". Solo así es posible comprender que "el hombre funde sobre él la legalidad, atribuyendo a Dios su origen. Porque de ese modo el cristiano, al acatar la autoridad por su origen divino, límite y fundamento de la misma, es a Dios a quien obedece, y no a la autoridad" ${ }^{10}$. De allí se deriva, también, la comprensión de que el hombre no está solo en el mundo, pues "la individualidad del hombre subsiste en la medida en que Dios la sostiene en el mundo y el hombre es individuo en el mundo y, por tanto, en la comunidad. Su relación ad se ipsum no es posible sin relación ad alterum" ". Por lo tanto, el hombre no deja el mundo librado a su suerte, sino que es responsable ante el mismo y también ante sus congéneres con los que funda la comunidad:

Dado, por tanto, que ser en el mundo, para el hombre, significa ser con los otros, la consideración del significado espiritual de la visibilidad debe partir de la constitución de una comunidad. En la medida en que sus miembros reciben su dignidad directamente de Dios, la comunidad no podrá anularlos, pero del mismo modo, únicamente a través de la comunidad puede relacionarse con Dios. Es así como se constituye la Iglesia visible ${ }^{12}$.

Dado que Dios asiste al hombre, evitando que el mundo lo engulla, este no solo no se encuentra solo, sino que debe permanecer atado a la comunidad en virtud de la obligación que lo vincula.

Decíamos antes que la forma en la cual el catolicismo comprende el vínculo entre Dios y el mundo diverge respecto de la teología protestante. De acuerdo a la lectura que Schmitt hace del protestantismo - deudora, en buena medida, de las reflexiones de Weber-, este produce la desvinculación entre Dios y el hombre, asentando tal ruptura, fundamentalmente, en la concepción de la total corrupción de la naturaleza humana. En este sentido, la teología protestante se apoya sobre una metafísica deísta que niega la posibilidad del milagro en el mundo en virtud del desgarramiento que existe entre la naturaleza y la gracia. Esta diferencia respecto del catolicismo - que no solo no niega la separación entre Dios y mundo, sino que, como vimos, los vincula a partir de la mediación eclesiástico-institucional, creada por la venida de Cristo, quien así volcó la gracia en el mundo-, es fundamental, puesto que, de esta manera, el hombre presume acceder a Dios - y por ello, a su salvación - de manera directa e individual y no a través de la mediación eclesiástico-sacramental. Al respecto, enuncia Schmitt in extenso:

También sería un sofisma, síntoma del más rudo materialismo o de una temeraria confusión entre el hombre y Dios, concluir de la soledad divina que el hombre,

\footnotetext{
$9 \quad$ Al respecto, anota Schmitt: "Una institución que haga valer lo invisible en lo visible tiene que arraigar en lo invisible y manifestarse en lo visible. Es el mediador quien desciende, porque la mediación sólo puede darse desde arriba y en sentido descendente, nunca al contrario, pues la salvación consiste en que Dios se hace hombre y no en que el hombre se convierta en Dios". Ibid., p. 14. Cursivas nuestras.

10 Ibid., p. 13.

11 Ibidem.

12 Ibidem.
} 
en su soledad física y psicológica, es lo más próximo a Dios — como si un todopoderoso Tamerlán fuera especialmente semejante a Dios y su omnipotencia- o que sus relaciones con él le concernieran en tanto individuo particular. La oración al Padre debe hacerse bajo la forma del Padrenuestro. Dios está solo y, sin embargo, en todas partes, también en el mundo. Ir hacia Dios no significa abandonar el mundo, desde el espiritualismo puro, como un objeto inconmensurable con lo religioso, ni tampoco considerar la legalidad del mundo como algo fundado en sí mismo. Ello significaría que lo mejor, lo más valioso, sería sólo una obligación respecto de una orden y no autoridad basada en la palabra de $\operatorname{Dios}^{13}$.

La Reforma protestante, por tanto, al pretender acceder a Dios brincando por encima de la mediación cristológica y de su instrumento eclesiástico, en un acto desesperado e impaciente por la salvación, lleva a término dos corolarios fundamentales. En primer lugar, la teología protestante habilita una negación de la instancia mediatriz eclesiástico-institucional, que deriva en la institución de la autoridad de las Escrituras, esto es, de la Biblia ${ }^{14}$. En segundo lugar, propicia el olvido del mundo al retraer la religiosidad del individuo a su propia interioridad como instancia salvífica $^{15}$. Este es el peligro ínsito a la teología protestante, pues niega la mediación y torna su mirada hacia el individuo, hacia el culto de lo individual. Sin embargo, de la extensa cita que hemos transcripto se desprende que la soledad solo puede predicarse de Dios, pues el hombre convive en comunidad con otros hombres. Por ello, el camino que el hombre debe transitar en su acercamiento a Dios no puede ser aquel que niega la comunidad, propio de la teología protestante, sino aquel que precisa la vida en comunidad. En este sentido remata Schmitt la crítica al protestantismo y la apología al cristianismo cuando indica que:

El verdadero cristiano no lo es por la impaciencia con que quiere llegar hasta Dios, sino por el camino que se propone para ello. Ese camino lo determina la ley de Dios; eso es el "pan rema", lo que Cristo opone al tentador cuando este le exige que convierta en pan las piedras. Su significado es el rechazo de la inmediatez, que quisiera saltar por encima del Mediador, de Cristo, y su instrumento, la Iglesia, para acallar el hambre de Dios ${ }^{16}$.

13 Ibid., p. 12.

14 Aquí la pregunta se hace evidente: Quis interpretabitur?, es decir, si el individuo es quien se relaciona con Dios y su libro sagrado, la Biblia, ¿quién tiene la potestad de la decisión última respecto del contenido de las Escrituras? Mantenemos en suspenso la respuesta, pues guarda analogía con el problema de la relación entre el individuo y los valores en el texto La tiranía de los valores, que será tratado en el apartado siguiente.

15 Este doble movimiento tiene sus raíces en la lectura que Ernst Troeltsch (1865-1923) hace del protestantismo. Troeltsch, teólogo contemporáneo y amigo de Weber, ya había advertido en el protestantismo la afirmación de una separación entre Dios y mundo y el concomitante rechazo de la mediación eclesiástica. De esta manera, el individuo se convierte en el juez último de las decisiones en torno a lo divino; de ahí que Troeltsch entienda que la fuerza vinculatoria con lo divino "se funda en primer lugar, en la última convicción personal y no en la autoridad dominante como tal", cuyo corolario es "un individualismo creciente de las convicciones, opiniones, teorías y fines prácticos". Ernst Troeltsch, El protestantismo y el mundo moderno, Fondo de Cultura Económica, México, D.F., 1979, p. 15. Insistimos: el protestantismo niega la fuerza vinculatoria de la mediación exterior, de la visibilidad de la Iglesia y de la autoridad papal y la sustituye por "la letra de la Biblia, captada por la fe" y, de este modo, "por una decisión personal de fe". Ibid., pp. 39 y 41.

16 Ibid., p. 12. Cursivas nuestras. 
Ya hemos elaborado lo suficiente el entramado teológico del catolicismo como para poder incardinar el aspecto jurídico-político que permite desarrollar el concepto de representación teológico-política de la obra schmittiana. Como ya hemos mencionado en la introducción, Schmitt encuentra este aspecto jurídico-político que hace a la continuidad entre lo teológico y lo político a través de la lectura de la obra de Hobbes ${ }^{17}$. Por ello, en el decir de Jorge Dotti:

La representación es el momento teórico donde se plantea el sentido de la eticidad religiosa del Estado, en tanto que el soberano se configura como tal en virtud de la continuidad que mantiene con la fundamentación de [la] Iglesia por parte de Cristo, esto es, en tanto la soberanía, eje portante de la estatalidad, es reconocida como institucionalidad político-ética por ser la prolongación de la dependencia de lo mundano respecto de lo trascendente ${ }^{18}$.

17 Si bien en su obra temprana Schmitt encuentra en la filosofía política de Hobbes la puerta de acceso para vincular "el Cielo y la Tierra" a partir de la continuidad jurídico-política que guardan Iglesia y Estado, no podemos soslayar el hecho de que Schmitt descubra en el Leviatán de Hobbes el germen de la propia destrucción del Estado. En un libro de 1938 titulado El Leviatán en la doctrina del Estado de Thomas Hobbes, Schmitt encuentra en la distinción entre fuero interno y fuero externo la supresión del alma del Leviatán y, consecuentemente, la neutralización y tecnificación que Schmitt rastrea en textos anteriores como El concepto de lo político o La época de las neutralizaciones y despolitizaciones. Este socavamiento del Estado se le imputa al judaísmo, en una sombría lectura sobre el presunto origen judío del símbolo del Leviatán. Asimismo, es el "judío liberal Spinoza" el responsable de poner a la luz la brecha entre el fuero interno y el externo que mina las bases del Estado: "Ya pocos años después de la publicación del Leviatán, cayó la mirada del primer judío liberal sobre la fisura apenas visible... También en Hobbes, la separación de interno y externo está presente, en los pasos citados sobre la fe en los milagros y la profesión de fe. Pero el filósofo judío desarrolla al máximo este germen hasta alcanzar lo contrario y el Leviatán queda privado de alma, desde adentro". Carl Schmitt, El Leviatán en la doctrina del Estado de Thomas Hobbes, Universidad Autónoma Metropolitana, Azcapotzalco, 1997, pp. 111-112. Las constantes invectivas de Schmitt contra el "frente judío" (ibid., p. 133) pueden comprenderse sobre la base de la filiación política del Jurist con el nacionalsocialismo y de la leyenda antisemita de la época. La literatura sobre la lectura que Schmitt dedicó a Hobbes es muy amplia y es imposible agotarla en nuestras pocas referencias: sobre el problema de la tecnificación del Estado, véanse John McCormick, "Fear, Technology and the State: Carl Schmitt, Leo Strauss, and the Revival of Hobbes in Weimar and National Socialist Germany": Political Theory, vol. 22, n. ${ }^{\circ}$ 4, (1994), pp. 619-652; y Marco Estrada Saavedra, “¿Protección a cambio de obediencia? El Leviatán en la lectura de Carl Schmitt”: Estudios Sociológicos, vol. XXI, n. ${ }^{\circ} 62$ (2003), pp. 363-398. Para una visión crítica de la lectura schmittiana de Hobbes y, fundamentalmente, de su aversión a manifiesta al espíritu judío véanse Yves Charles Zarka, "Carl Schmitt, una lectura antimoderna de la modernidad: la triple traición a Hobbes": Eikasia. Revista de filosofia, n. 45 (2012), pp. 57-70; y Paul Bookbinder, "Carl Schmitt, 'Der Leviathan', and the Jews": International Social Science Review, vol. 66, n. 3 (1991), pp. 99-109.

18 Jorge Dotti, “Algunas consideraciones sobre el concepto hobbesiano-schmittiano de representación”, en Donato R. Oscar Mauricio y Pablo Elías González Monguí (comps.), Memorias del Simposio Internacional Carl Schmitt. Análisis crítico a su obra jurídica, política y filosófica, Universidad Libre, Bogotá, 2010, p. 4. En este paso textual no parece quedar suficientemente claro si el Estado moderno se legitima dado que representa efectivamente la sustancia divina fundadora; sin embargo, otros pasajes de otro texto del autor abonan esta exégesis, verbi gratia: "El Estado, entonces, se legitima en su condición de estructura inmanente en que se representa la sustancia trascendente sobre la cual se legitima como ejercicio soberano. Si así no fuera, el sentido del orden estatal quedaría reducido al de un mero dispositivo utilitario que la exacerbada subjetividad moderna construye en aras de la obtención de la máxima utilidad personal de sus constructores". Jorge Dotti, "La representación teológico-política en Carl Schmitt”: Avatares filosóficos, n. ${ }^{\circ}$ 1. (2014), p. 30. Cursivas nuestras. Compárese esto con Carlo Galli, para quien, si bien existe una continuidad entre teología y política, esta no refiere al fundamento sustancial divino, sino a la necesidad del orden: "Ésta es la teología política en sentido estricto: para Schmitt, no es la deducción de la política de la teología, sino más bien la teoría según la cual la política moderna (sus conceptos, sus instituciones) conserva algo de la religión, y precisamente lo que conserva es el vaciamiento y no la superación de sus conceptos teológicos (sobre todo de la unidad del orden y de su creación soberana). En resumen, conviene repetirlo, la relación entre la política (moderna) y la tradición teológica es doble: por una parte, a diferencia de la teología, la política se estructura sobre la ausencia de sustancia divina fundativa, pero 
El momento teológico-político, por lo tanto, cobra existencia a partir de la modulación secularizada que recibe la Segunda Persona de la Trinidad (el Hijo de Dios, Cristo, el Mediador). Pues, si como hemos recuperado en nuestra restitución de la doctrina católica, Dios (Primera Persona del dogma tridentino) se hace hombre en Cristo o, dicho de otro modo, hace de Cristo la presencia concreta de lo alto en lo bajo, de lo trascendente en lo inmanente, de lo sempiterno en lo transeúnte, instituyendo la Iglesia como mediación capaz de redimir a la humanidad en la Tierra; el Estado, en un plano jurídico-político, encuentra en esa analogía con la mediación cristológica, la legitimidad que hace posible el orden estatal. En otro texto, explica Dotti que "la dignificación del mundo por Jesús el Cristo, es decir, el Salvador y Mesías, instaura en la conciencia de los humanos un sentido espiritual de pertenencia a un orden político, que no es reducible a términos de racionalidad simplemente pragmática ni, menos aún, a mero ejercicio de fuerza"19. Esta forma de pensar la mediación estatal contrasta con la racionalidad pragmática a la que alude Dotti, cuya referencia encontramos en el pensamiento liberal y que impide acatar de forma legítima la autoridad estatal, pues parte del dato del individuo ${ }^{20}$ como fundamento del orden y no de la idea de que todo poder proviene de Dios. Por ello prosigue Dotti:

Correlativamente, sobre esta espiritualidad se funda la obediencia a la ley antes del temor a la coacción. La doble faz de la ley guarda correspondencia con la dualidad en unidad propia de lo teológico-político. Para el soberano, mirar el Cielo es mirar la Tierra; mirar la Tierra es mirar el Cielo; el ciudadano respetuoso de su deber de obediencia visualiza ambos hontanares de la legalidad estatal ${ }^{21}$.

En suma, esta mediación teológico-política refiere a una estructura en cruz — de claras alusiones a la crucifixión de Jesucristo-, que se apoya en la intersección entre una directriz vertical, enraizada en una institución que permite el descenso de lo trascendente en lo inmanente, y otra horizontal, asentada en la igualdad de las relaciones entre los actores movidos por una racionalidad de tipo utilitaria. Esta estructura en cruz adquiere su fundamento, por tanto, en "el respeto de la legalidad del orden estatal como representación en conformidad al encuentro crucial entre lo alto y lo bajo" ${ }^{22}$. En resumidas cuentas, el racionalismo que fundamenta tanto a la Iglesia como al Estado no es el racionalismo técnico-instrumental propio del afán utilitarista del liberalismo, sino un racionalismo que reside en lo "institucional y es esencialmente jurídico"23. El Papa no es un profeta, sino el vicario de Cristo en la Tierra; la dignidad de su oficio sacerdotal no le es conferida ni por su carisma, ni por

por otra parte reproduce de ésta, aunque sólo de manera formal y racional, la función ordinativa monista". Carlo Galli, La mirada de Jano, Fondo de Cultura Económica, Buenos Aires, 2011, p. 79. No es una apuesta de este trabajo zanjar la discusión, pero sí dejar planteado el problema.

19 Dotti, La representación teológico-política en Carl Schmitt, p. 33.

20 Este giro hacia el individuo operado a partir del liberalismo sigue, como hemos sugerido al principio de este trabajo, la estela de la teología protestante y su comprensión sobre la relación entre el individuo, el mundo y Dios, tal cual hemos restituido, grosso modo, unos párrafos más arriba.

21 Ibidem.

22 Ibid., pp. 32-33.

23 Carl Schmitt, Catolicismo romano y forma política, Tecnos, Madrid, 2000, p. 17. Con esta afirmación Schmitt permite trazar una analogía entre la forma romana de la Iglesia católica y la forma política del Estado moderno, asentando dicha analogía en el derecho canónico, vehículo a partir del cual se secularizan las ideas políticas. 
su persona, sino porque "se liga, en una cadena ininterrumpida, al encargo personal y a la persona de Cristo" 24 . En este sentido, el soberano es al Estado lo que el Papa es a la Iglesia y sus funciones se dignifican pues representan y realizan la Idea - Idea del Reino de Dios o la Idea del Derecho_- en suma, la realización de lo trascendente en lo inmanente, de lo alto en lo bajo.

Es en este punto - en la cuestión de la Idea del Derecho, de la pregunta por lo justo y lo bueno - donde podemos vincular la representación teológico-política ya desarrollada con el problema de los valores. Pero antes, debemos esbozar la crítica a la filosofía de los valores que Carl Schmitt suscita en Die Tyrannei der Werte. Para ello, restituiremos, en el próximo apartado, los argumentos que allí se indican en torno a la problematicidad de esa comprensión de la relación entre el individuo y los valores, planteando, asimismo, una vía de escape de carácter teológico-político.

\section{La filosofía de los valores como respuesta y radicalización del nihilismo}

El interés por los valores tiene su origen en una "situación histórico-filosófica" muy precisa: la crisis nihilista del siglo diecinueve. Para Carl Schmitt — mediado por la lectura de Martin Heidegger (1889-1973) — es Friedrich Nietzsche (1844-1900) quien en sus escritos fue capaz de popularizar el discurso sobre los valores. Al respecto anota Schmitt in extenso:

Una ciencia cuyas leyes son causales y que es, por ello, prescindente de valores, amenazó la libertad del hombre y su responsabilidad religiosa, ética y jurídica. La filosofía del valor respondió a este desafío al contraponer al ámbito de un ser determinado de modo puramente causal un ámbito de los valores, es decir: un ámbito del valer ideal. Fue un intento de afirmar al hombre como un ser libre y responsable, no por cierto a partir de un Ser, pero sí al menos a partir de la validez de aquello que se dio en llamar valor ${ }^{25}$.

De lo citado es preciso notar algo: "el valor no es, sino que vale"26, es decir, no es preciso que tenga ser, sino que requiere validez. Porque el valor vale, debe hacerse valer. Esto que parece un pleonasmo nos dice algo más del valor; a saber, que este implica un impulso a su realización o, dicho de otro modo, supone que el valor ansía su actualización. En suma, supone que el valor, para estar referido a la realidad, precisa ser ejecutado y cumplido. Ante esto, surge un interrogante: ¿quién pone los valores? O, dicho más schmittianamente, ¿quién decide sobre los valores? Frente a esta pregunta, Schmitt recupera, en primer lugar, la figura de Weber. Para Weber, es el individuo humano, quien, completamente libre para decidir, pone los valores. Pero esta postura cae víctima de un problema palmario: "la libertad puramente subjetiva de la posición de valores conduce empero a una lucha eterna de los valores y las cosmovisiones, a una guerra de todos contra todos, a un eterno bellum ómnium

Dicho en otras palabras, el racionalismo que permite al Estado adoptar la forma secularizada de la Iglesia católica, es un racionalismo jurídico-institucional, apoyado sobre la forma jurídica del derecho canónico.

24 Ibidem.

25 Carl Schmitt, La tiranía de los valores, Hydra, Buenos Aires, 2010, p. 129.

26 Ibid., p. 125. 
contra omnes" ${ }^{27}$, donde hombres desesperados por tener razón luchan entre sí, mas ahora acompañados por espantosos medios de exterminio, abominables productos de la ciencia prescindente de valores. En suma, una lucha de valores en dónde "[1]o que para uno es el Diablo, para otro el Dios"28.

Schmitt ubica una segunda respuesta a la pregunta en torno a quién pone los valores en la filosofía material de los valores de Max Scheler (1874-1928). Este autor, en su intento de escapar del subjetivismo weberiano de los valores - que no constituía una respuesta adecuada al nihilismo, pues caía ella misma en el nihilismo-, erigió, de acuerdo con la lectura de Schmitt, un sistema ascendente de valores organizado según niveles, yendo de lo útil a lo santo. Era un intento por superar la doctrina neokantiana de los valores, cuyo formalismo, subjetivismo y relativismo impedía el acceso a lo que se buscaba, esto es: "el sustituto científico para un Derecho Natural que ya no proporcionaba legitimidad" 29 . Sin embargo, como recalca el propio Schmitt, "sean los valores tan elevados o santos como se quiera, sólo valen como valores para algo o para alguien" ${ }^{\prime 3}$. Esto significa que los valores son nulos si no se imponen. Como afirmamos con anterioridad, la validez de los valores debe ser constantemente actualizada, lo que significa que a los valores se los tiene que hacer valer para no quedar disueltos en una mera apariencia. En el decir de Schmitt: "quien dice valor quiere hacer valer e imponer... a las normas se las aplica; las órdenes se ejecutan; pero los valores se ponen e imponen. Quien afirma su validez tiene que hacerlos valer. Quien dice que valen sin que un hombre los haga valer, quiere engañar"31.

Si la filosofía material del valor ha sido desechada por Schmitt, debemos suponer que los valores son puestos por el individuo y, en virtud de ello, toda filosofía del valor es una filosofia formal y subjetiva del valor. En este sentido apunta Schmitt cuando dice que "la filosofía del valor es una filosofía de lo puntual, la ética del valor es una ética de lo puntual" 32 . De este modo, el valor de algo sólo puede ser determinado a partir del punto en el que nosotros miramos. Por ello, los valores no son más que puntos, puntos ubicables en un sistema de referencias, donde incluso el valor supremo ocupa solo una ubicación. "Por ello la expresión 'transvaloración de todos los valores' pudo entrar en circulación sin sobresaltos" ${ }^{\text {"33 }}$. Toda vez que cambiamos de punto de posicionamiento, de punto de mirada, la transvaloración tiene lugar. Una vez aceptado el puntualismo inmanente a todo pensamiento según valores, Schmitt evoca nuevamente el pensamiento de Weber e introduce un concepto que pertenece, también, a la estructura de todo valor, a saber, el punto de ataque. Para Weber, las valoraciones presentan puntos de ataque, que develan, en toda posición de valor, una agresividad que le es inmanente. A partir de esta idea de agresividad Schmitt pretende borrar el relativismo, el perspectivismo y la tolerancia a la que fue asociado el pensamiento según valores. Sin embargo, el "fatal envés de los valores" es su

27 Ibid., p. 130.

28 Ibidem. Este problema al que conducía el planteo weberiano de los valores ya había sido observado de un modo casi idéntico por Leo Strauss. Véase Leo Strauss, "Derecho natural y la distinción entre hechos y valores", en Derecho natural e historia, Prometeo, Buenos Aires, 2014. En efecto, nos aventuramos a decir que Schmitt hace un uso parafrástico del análisis straussiano del pensamiento de Weber.

29 Schmitt, La tiranía de los valores, p. 108.

30 Ibid., p. 131.

31 Ibid., p. 132.

32 Ibidem.

33 Ibid., p. 133. 
agresividad inherente que ocluye a la filosofía de los valores la posibilidad de superar el subjetivismo del diagnóstico weberiano, pues, como anota Schmitt:

Nadie puede valorar sin desvalorizar, valorizar o poner en valor. Quien pone valores ya confronta con los no-valores. La ilimitada tolerancia y neutralidad de posiciones y puntos de vista arbitrariamente intercambiables se convierte al punto en su contrario, en enemistad, tan pronto como las cosas se ponen seriamente concretas con el imponer y el hacer valer. El impulso hacia la validez del valor es irresistible y la contienda de quienes valoran, desvalorizan, valorizan y ponen en valor, inevitable ${ }^{34}$.

El fatal envés de los valores radica, por tanto, en que para hacerse valer somete los valores más bajos y aniquila los no-valores. De esta fatalidad se desprende el concepto de "tiranía de los valores" que Schmitt recupera de la filosofía de Nicolai Hartmann (1882-1950). La tiranía de los valores está a la vista, pues los valores, para hacerse valer aniquilan el disvalor y someten a los valores más bajos. La tiranía de los valores solo devela y evidencia la honestidad del diagnóstico weberiano: "que la doctrina del valor en su totalidad sólo atiza e incrementa la antigua y prolongada lucha de las convicciones y los intereses" 35 . Bajo la tiranía de los valores, el fin justifica los medios y la aniquilación del no-valor por el valor está justificada. "La negación de un valor negativo es un valor positivo", decía Scheler. El Jurist responde: "aquella proposición de Max Scheler permite devolver mal por mal y de este modo convertir nuestra tierra en un infierno; al infierno, empero, en un paraíso de valores" 36 . Fiat iustitia, pereat mundus.

La locución latina que culmina el párrafo precedente cobija en sí misma gran parte del problema que la filosofía de los valores plantea para el jurista alemán. El problema reside, como es evidente, en que el diagnóstico weberiano respecto de los valores parece insuperable: el individuo es quien decide sobre el valor a imponer, cuyo corolario es la ya mentada lucha eterna entre los valores, la guerra de todos contra todos en torno al valorar. Aquí lo esencial es detectar que la filosofía de los valores se apoya sobre una metafísica que se remonta a la teología protestante y al liberalismo ${ }^{37}$, en la medida en que, como vimos, la teología protestante, al negar la mediación eclesiástico-instrumental, instituye, consecuentemente, la autoridad de la Biblia; y el liberalismo, al negar la mediación estatal, establece una relación directa entre el individuo y la Idea de lo justo (el valor). Ahora bien, esto supone dos cuestiones: (i) o bien Dios y la Idea de lo justo son racionalmente cognoscibles en virtud de la transparencia de las Sagradas Escrituras y de la Idea de lo justo; o (ii) la pluralidad

\footnotetext{
Ibid., p. 138. Cursivas nuestras.

Ibid., p. 140.

Ibid., p. 143.

37 En su "Filioque" Dotti elabora una interesante genealogía económica — de raigambre judía - respecto de la lógica del valor, en donde Marx y Schmitt dialogan entre sí. Véase Jorge Dotti, "Filioque: Una tenaz apología de la mediación teológico-política", en Carl Schmitt, La tiranía de los valores, Hydra, Buenos Aires, 2010, pp. 9-86. Por cuestiones que exceden el marco de este trabajo, no podemos analizarlo aquí. No obstante, sí tomamos la indicación de Dotti de que "la lógica del valor, en cuyo seno se genera un topo específico de representación inmanentista, lejos de ofrecer una suerte de refuerzo doctrinario a las posiciones contrarias al positivismo cientificista, al economicismo y al relativismo, lleva a conclusión la liquidación de la mediación teológico-política como respaldo sustancial de la institucionalidad moderna (El Estado) en su período clásico, previo a la era de masas". Ibid., p. 72.
} 
de lecturas de la Biblia y de relaciones con lo justo es plenamente armonizable. En lo que respecta a los valores, que es lo que aquí nos interesa, no es posible abonar tal optimismo, puesto que, insistimos, la relación individual con los valores solo conduce a una reyerta mortal en la que el valor aniquila al no-valor, a aquello que intenta negarlo. Como escribe Dotti en su "Filioque", "quien se unge a sí mismo hermeneuta y ejecutor absoluto (i.e. absuelto de otra obligación que no sea la que él se ha impuesto) se lanza al enfrentamiento despiadado con quien hace lo mismo, pero desde una toma de posición negativa y excluyente, por ende intolerable"38. La antipoliticidad de la axiología reside precisamente en que cada individuo, como mienta Dotti, se erige como dueño de la interpretación absoluta sobre la Idea de lo justo, en virtud de lo cual cualquier medio es válido y toda violencia se halla plenamente justificada.

Para Dotti, este dinamismo ínsito al Wert, al valor y a su lógica económica ha logrado neutralizar, finalmente, la mediación institucional teológico-política, esto es, la cruz que intersecta el fundamento transcendente y la visibilidad en la inmanencia. Nuestra lectura, en cambio, sugiere que Schmitt no abandona la posibilidad de pensar los valores bajo un sustrato teológico-político que permita fundar un orden concreto. A propósito, el último apartado de la edición privada de 1960 de La tiranía de los valores, intitulado "Ejecución no mediada y legalmente mediada del valor" contiene una pista que respalda nuestra hipótesis:

La Idea necesita la mediación y cuando hace su aparición en desnuda inmediatez o en auto-ejecución automática, allí surge entonces el terror y la desgracia es temible. Hoy en día tendría que darse por obvia la misma verdad, pero aplicada a aquello que se llama valor. Sin lugar a dudas, hay que reflexionar al respecto toda vez que se quiere sostener la categoría "valor". La Idea requiere mediación, pero el valor la requiere aún más ${ }^{39}$.

Esta enigmática cita puede ser aclarada si volvemos hacia los primeros textos de Carl Schmitt, fundamentalmente a aquel de 1914, El valor del Estado y el significado del individuo, donde la pregunta por el valor, por la Idea de lo justo, contrasta de modo palmario con la recuperación que el Jurist realiza de la filosofía de los valores en La tiranía de los valores. Concluiremos este trabajo, entonces, recuperando los argumentos allí trazados para dar cuenta de lo que hemos dado en llamar "la teología política de los valores".

\section{Hacia una teología política de los valores}

Una de las premisas que guía a El valor del Estado y el significado del individuo es la relación que se establece en la serie tríadica entre Derecho, Estado e Individuo. Al respecto, anota Schmitt:

El Derecho, como norma pura, valiosa en sí, no fundada en hechos, constituye el primer miembro de esta serie. El Estado es quien ha de poner en contacto ese

Ibid., p. 84.

Schmitt, La tiranía de los valores, p. 146. Cursivas nuestras. 
mundo ideal y el mundo de los hechos reales y constituye el único sujeto del ethos jurídico. El individuo, por último, en tanto ser empírico y único, desaparece, dentro del Derecho y el Estado, para ser considerado sólo función de la realización del Derecho y recibir así su significado de un deber y su valor de un mundo ideal encerrado en sus propias normas ${ }^{40}$.

Este extenso paso alberga el núcleo central del argumento. Una de las preocupaciones que anuda el texto gira en torno a la relación entre el Derecho y el Poder. Si el Derecho se asienta simplemente en la violencia de las relaciones fácticas de poder, este permanecería en la pura positividad de la ley. Sin embargo, hemos de constatar que cuando se afirma "que quien tiene Poder tiene Derecho..., lo que en realidad se manifiesta en esa misma afirmación implícitamente, palabra por palabra, es la confianza en un reconocimiento más alto; y lo que en verdad significa es que no hay Poder establecido que no esté justificado"41. De ambas citas se constata que el Derecho pertenece a un plano más alto, a un plano ideal, esto es, a la Idea del Derecho, a la pregunta por lo justo y lo bueno, y que por ello no puede deducirse de la pura inmanencia de lo dado. En suma, esto supone que todo orden, para concretarse, supone la distinción entre lo justo y lo injusto, lo bueno y lo malo; supone, pues, que "estamos ante dos mundos situados frente a frente" 42 : por un lado, la Idea del Derecho; por el otro, la realidad empírica. La inmanencia de lo concreto es horadada por una trascendencia que le da sentido. De este reino del Derecho se deriva der Wert, el valor: "El reino del Derecho no conoce de ningún tipo de límites fácticos: la facticidad maneja causas y consecuencias, pero no valores, lo alto y lo bajo" 43 . Ahora bien, "el Derecho es un pensamiento abstracto, no es deducible de hechos ni puede afectar a hechos; sujeto de la 'realización' del Derecho, del querer recto, sólo podrá ser, por tanto, una realidad" 44 . El Derecho - el valor — no puede realizarse a sí mismo, requiere de una realidad concreta que enlace ambos reinos, que consiga "realizar en el Ser la ejecución de las normas en su recto sentido" 45 : ¿quién es este sujeto portante del ethos jurídico? Ya lo hemos anticipado más arriba: el Estado.

En este punto es donde somos capaces de vislumbrar el carácter teológico-político del valor. Si este depende de la realización del Derecho, a cargo de la mediación del Estado, solo el concepto de representación teológico-política que hemos repuesto permite su comprensión. De hecho, el valor del Estado se deriva precisamente del encargo que le fue solicitado, esto es, de la realización del Derecho:

En el medio de esta tripartición se encuentra el Estado. De la contraposición entre norma y mundo empírico nace la posición del Estado como punto de transición entre un mundo y otro. En él, como piedra angular, se pasa del Derecho, como puro pensamiento, al Derecho como fenómeno terrestre. El Estado es por eso una

\footnotetext{
40 Carl Schmitt, El valor del Estado y el significado del individuo, Centro de Estudios Políticos y Constitucionales, Madrid, 2011, p. 4. Cursivas nuestras.

41 Ibid., p. 19. Cursivas nuestras.

42 Ibid., p. 24.

43 Ibid., p. 27. Cursivas nuestras.

44 Ibid., p. 28.

45 Ibidem.
} 
forma jurídica, cuyo sentido está exclusivamente en la tarea de realizar el Derecho, forzando un estado en el mundo exterior ${ }^{46}$.

Lo mismo puede decirse del individuo. Este no existe en virtud de su magnitud empírica, sino por entregarse a la magnitud impersonal y supra-empírica del Derecho, realizado por el Estado. "Lo esencial aquí está, sin embargo, en que en el pensamiento consciente la devoción por la ley y el valor del pensamiento recto residen en que el individuo casual y singular desaparece para entrar a participar de un valor extra-individual, y que sólo merece el predicado 'ser' lo susceptible de ser valorado" ${ }^{47}$. Ese valor extra-individual, del cual participa el individuo y del cual obtiene su significado y su dignidad es la norma, la ley: "un ser racional tan exigente no puede depender de procesos empíricos sino de la participación en un valor al que una norma, como diría Kant, constituye" ${ }^{48}$. De ahí que Schmitt reste importancia a Julio César (100-44 a. e. c.), Federico II el Grande (1712-1786) u Otto von Bismarck (1815-1898) en tanto individuos concretos y particulares, puesto que "la grandeza de los hombres está en la grandeza de su tarea y su ejecución". Lo que hizo grandes y admirables a esos hombres fue su identificación con el deber, su entrega absoluta a una causa, el orgullo de servir a su Estado, el olvido de sí mismos. En suma, "todo el valor que puedan tener los individuos descansa en su entrega al ritmo supra individual de una legalidad. En el mundo del Estado es donde ha llegado a realizarse con más claridad este principio fundamental para el esclarecimiento de los valores"49. Si el valor se constituye, como hemos mentado, en virtud de una norma; esta se realiza mediante el Estado y el individuo adquiere su dignidad por participar de ese valor supra-individual, debemos advertir que es el concepto de representación teológicopolítica el que nos permite interpretar adecuadamente esta estructura del valor que replica la mediación cristológica. La teología política de los valores remite pues, a la realización del Derecho - de la Idea de lo justo - a través de la mediación institucional del Estado que funda el orden normativo y garantiza la pacífica convivencia de las pluralidades humanas.

Sin embargo, cabe hacer una última advertencia: la Idea del Derecho jamás es plenamente realizable, pues esto supondría la realización en la Tierra del reino del Derecho y, en consecuencia, del fin de la Política. Por tanto, "si el dualismo es reconocido y admitido en el Derecho, conviene entonces, en protección de las normas abstractas, someter a control su proceso de positivización". En ello se justifica la doctrina católica de la infalibilidad papal, que ha recibido la competencia para declarar que las leyes del Estado que contradigan las ius divino-naturale no obligan en conciencia. Sin embargo, "ninguna ley puede erigirse a sí misma, siempre son sólo hombres los que pueden ser erigidos en guardianes de las leyes" ${ }^{50}$; hemos de renunciar a la justicia intemporal, pues la humanización del Derecho, nos induce a pactar con los poderes del mundo real ${ }^{51}$. Aquí radica la tragedia de la existencia humana, pues no pudiendo agotar y realizar plenamente la Idea, habilita un conflicto entre

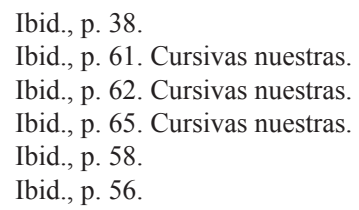


ella y lo fáctico. La realización trágica — por ser incompleta - de la Idea requiere la representación: el soberano, la auctoritas interpositio, pues "ningún sistema político puede perdurar una sola generación valiéndose simplemente de la técnica del mantenimiento del poder. La Idea es parte de lo Político, porque no hay política sin autoridad y no hay autoridad sin un Ethos de la convicción" 52.

\section{Consideraciones finales}

El modo en el que Carl Schmitt configura su teología política de los valores ha sido estructurada en tres apartados. En el primero hemos recuperado la noción de representación teológico-política a través de la contraposición que el jurista alemán rastrea entre catolicismo y protestantismo en función de su acceso a Dios. Si la Reforma protestante, de acuerdo a la reconstrucción que Schmitt hace de las lecturas de Weber y Troeltsch, permite el acceso inmediato del individuo a Dios en virtud de la negación de los sacramentos y de la institución mediadora de la Iglesia, erigiendo las Escrituras bíblicas como la máxima autoridad e introyectando la religiosidad al fuero interno individual, el catolicismo, por su parte, establece el vínculo entre Dios y el individuo por medio de la institución eclesiástica. En este sentido, el hombre no vive en soledad; antes bien, convive en comunidad con otros hombres, una comunidad dotada de sentido, porque, mediada por la representación de la Iglesia, participa de lo alto, de lo divino, de la gracia de Dios. Y de esa continuidad formal con la representación eclesiástica, como vimos, deriva la representación teológico-política del Estado, cuya estructura en cruz permite la convivencia de los individuos en la comunidad política.

En el segundo apartado hemos reconstruido el debate en torno a los valores propiciado en Alemania durante fines del siglo diecinueve y principios del siglo veinte. Ahí descubrimos la dificultad en la que se encontró la filosofía de los valores para superar el diagnóstico weberiano del pluralismo axiológico. Es que el intento de ir más allá de un relativismo axiológico sostenido sobre la base de un individualismo valorativo solo condujo hacia un nihilismo de mayores proporciones, culminando en los aciagos episodios de exterminio y totalitarismo nazis. La puesta en valor, como dejamos señalado, tenía su reverso en la desvalorización del otro, cuyo único final se jugaba en su aniquilación. De ahí la elocuencia de Nicolai Hartmann (1882-1950) al acuñar el término "tiranía de los valores" 53 . De ahí, también, la lucidez de Weber, al señalar el relativismo axiológico y la consecuente guerra de todos contra todos en torno a los valores.

De modo que ante la pregunta por los valores, Weber no pudo ofrecer más que desesperanza: si a pesar de su brillante lucidez, quedó atrapado bajo una concepción individualista de los valores y declaró, en consecuencia, su carácter irresoluble, fue Schmitt quien, tomando como punto de partida el diagnóstico weberiano respecto de los valores y sus investigaciones en torno a las religiones y los modos de vida - legado weberiano que, insistimos, no podemos dejar de observar en la obra del Jurist - , supo encontrar en la tradición católico romana una vía de acceso a la resolución del problema de los valores. Ante la neutralidad axiológica y su anverso, la guerra de todos contra todos en torno a la imposición de los valores, Schmitt, como

Schmitt, Catolicismo romano y forma política, p. 21.

53 Nicolai Hartmann, Ética, Ediciones Encuentro, Madrid, 2011, pp. 612-615. 
vimos en el tercer apartado, nos invita a pensar en una relación mediada del hombre con los valores, apoyada sobre la representación de la persona soberana, esto es, sobre la autoridad del Estado.

A la vista de estos tres ejes a partir de los cuales se delineó lo que hemos denominado una teología política de los valores, resulta interesante recuperar la pregunta que formulamos al comienzo respecto del vínculo entre los valores y una de las obras centrales de Schmitt, El concepto de lo político ${ }^{54}$. Se decía entonces que la posibilidad de la guerra devenía efectiva en la medida en que una unidad política ponía en riesgo el modo de vida de otra unidad política y, en virtud de ello, nos interrogábamos respecto de la configuración de ese modo de vida. En este sentido, si bien El concepto de lo político parece guardar silencio respecto de la cuestión de los valores que dan sentido a la comunidad política, es muy tardíamente, en una nota al pie que Schmitt incorpora a una nueva edición de El concepto de lo político, cuando él provee una clave hermenéutica a partir de la cual interpretar ese texto en línea con la cuestión axiológica. Hacemos alusión a la referencia sobre der HobbesKristall ${ }^{55}$, introducida por Schmitt en 1963, en donde, en razón de una discusión en torno al problema de la "naturaleza" del hombre y el origen de las guerras, Schmitt construye un sistema, inspirado en la filosofía política de Hobbes, en cuyo pináculo se distingue la apertura a la trascendencia. Sobre lo alto de la estructura en forma de cristal Schmitt coloca la veritas "Jesús es el Cristo". Sin embargo, esta verdad exige la pregunta Quis interpretabitur?, esto es, requiere una interpretación, a la cual se responde con la máxima Auctoritas, non veritas, facit legem; es decir, se responde con la evocación de una potestas directa, capaz de garantizar protección a cambio de obediencia, creando una cadena que de lo alto a lo bajo nos guía de la verdad del culto público hacia la obediencia y la protección del individuo. De modo inverso, como indica Schmitt, "la cadena parte de la exigencia de protección y de seguridad del hombre aislado, 'por naturaleza' necesitado de consejo y de ayuda, y de la obediencia de él conseguida, y conduce, a lo largo del mismo camino pero en una situación invertida, a la puerta abierta hacia la trascendencia" ${ }^{" 56}$. Es el Estado, por lo tanto, quien interpreta el culto público que da sentido a la unidad política y en virtud del cual se neutralizan los conflictos civiles. Sin embargo, Schmitt va aún más allá al dejar entrever que la verdad del culto público es permutable:

De inmediato surge la cuestión de si tal neutralización puede ser extendida, más allá de la común creencia en Jesucristo, también a la común fe en Dios — en tal caso el primer punto podría también sonar: Alá es grande-, o directamente también a alguna de las muchas verdades necesitadas de interpretación, a los ideales sociales, a los valores y a los principios supremos, en cuya realización y aplicación se originan los conflictos y las guerras: por ejemplo "libertad, igualdad, fraternidad"57.

Si la distinción amigo-enemigo posee un carácter existencial, esto es, si da cuenta de la existencia de un pueblo en tanto unidad política, esto es así porque existen

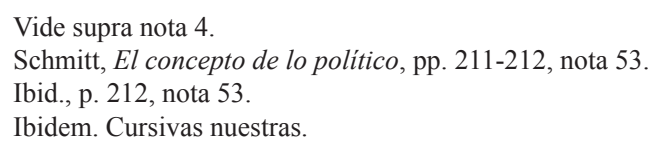


ciertos valores que configuran el modo de vida de un pueblo y lo conducen a la guerra en cuanto aquella forma de vida se vea obliterada. Todo óbice a la forma de vida de una unidad política es condición de posibilidad de la guerra, cuya potencialidad está expresada en la distinción eminentemente política de amigo-enemigo. Por lo tanto, si el Estado es el exégeta de esos cultos públicos, de esos valores que vinculan a los individuos a la comunidad y a la unidad política y los conducen a la defensa de esa unidad, no podemos dejar de subrayar, entonces, la utilidad del concepto de representación teológico política y, por tanto, de la teología política de los valores en el pensamiento de Carl Schmitt.

Llegados a este punto en la comprensión del pensamiento de Schmitt y en línea con el programa straussiano de una historia no historicista de la filosofía política, estamos en condiciones de proceder con el distanciamiento crítico. En este sentido, es plausible indicar que la distinción "amigo-enemigo" ha sido revisitada a lo largo del siglo veinte y veintiuno, siendo objeto de crítica por parte de pensadores de la tradición democrática ${ }^{58}$. Si bien Chantal Mouffe ha revalorizado los trabajos de Schmitt al destacar el carácter conflictivo de las relaciones humanas $\mathrm{y}$, consecuentemente, de lo político, ha modificado, sin embargo, la distinción amigo-enemigo por aquella de amigo-adversario, motivada por sus reflexiones en torno a la democracia. Un gesto similar ha sido llevado a cabo por Franz Hinkelammert, cuando somete a crítica la denuncia schmittiana al humanismo en su artículo "El concepto de lo político según Carl Schmitt". De acuerdo con Hinkelammert, la crítica schmittiana del humanismo no logra escapar del peligro que denuncia, es decir, al criticar a aquellos que en nombre del humanismo y de la paz "crean imágenes de enemigos absolutos, Schmitt está creando por su parte una nueva imagen de enemigo absoluto, que es incompatible con su promesa utópica de la relación amigo-enemigo real". Y más adelante agrega: "Así surge la utopía más destructora que se conoce. Se trata de la utopía antiutópica que promete la humanización por la destrucción del humanismo...Se vislumbra el milenarismo nazi del Tercer Reich: en vez de la batalla final utópica, el exterminio total (Endlösung) antiutópico"59. La crítica final de Hinkelammert pretende denunciar el fondo nihilista del concepto de lo político schmittiano en una línea que lo enlaza con Nietzsche: "En sentido estricto, se deriva de esta definición que ni humanidad ni paz ni justicia ni progreso ni civilización son conceptos políticos. Lo político se agota en la voluntad de poder. El nihilismo más absoluto es el resultado" $"$.

Es ostensible que las reformulaciones en torno al problema del relativismo axiológico presentes en la ética del discurso, el comunitarismo o la teoría del reconocimiento han sido motivadas por Auschwitz. Es que los denodados intentos de Jürgen Habermas por elaborar una ética universal apoyada en la razón argumentativa — similares a los esfuerzos empleados por Charles Taylor o Axel Hönneth- deben comprenderse a la luz de los problemas teórico-normativos que fueron abiertos por los totalitarismos tanto como a los planteados por la democracia. Por ello, una reflexión

58 Aquí destacamos a Chantal Mouffe y Franz Hinkelammert. Véanse Chantal Mouffe, En torno a lo politico, Fondo de Cultura Económica, Buenos Aires, 2007; y Franz Hinkelammert, "El concepto de lo político según Carl Schmitt", en Norbert Lechner, Cultura política y democratización, CLACSO-FLACSO-ICI, Santiago de Chile, 1987, pp. 235-251.

59 Hinkelammert, "El concepto de lo político según Carl Schmitt", p. 242.

60 Ibid., p. 245. 
atenta al problema de los valores no puede soslayar los aportes de Carl Schmitt. Sus reflexiones en torno a los valores presentan una formulación teórico-política especialmente valiosa del problema. En este sentido, aunque parece plausible que su crítica del concepto humanidad, como se desprende del artículo de Hinkelammert, abole la posibilidad de valores humanos, su teología política de los valores pone en evidencia el carácter eminentemente axiológico de la naturaleza humana, el hecho de que somos seres axiológicos. Por ello, en esa intuición se funda nuestra necesidad de abrazar la democracia y la pluralidad como un valor inclaudicable, en cuya realización el Estado ocupa un lugar eminente.

\section{Referencias bibliográficas}

Bookbinder, Paul, “Carl Schmitt, 'Der Leviathan', and the Jews": International Social Science Review, vol. 66, n. ${ }^{\circ}$ 3, (1991), pp. 99-109.

Dotti, Jorge, "Algunas consideraciones sobre el concepto hobbesiano-schmittiano de representación", en Oscar Mauricio Donato R. y Pablo Elías González M. (comps.), Memorias del Simposio Internacional Carl Schmitt. Análisis crítico a su obra jurídica, política y filosófica, Universidad Libre, Bogotá, 2010.

—, "Filioque: Una tenaz apología de la mediación teológico-política", en Carl Schmitt, La tiranía de los valores, Hydra, Buenos Aires, 2010, pp. 9-86.

—, "La representación teológico-política en Carl Schmitt": Avatares filosóficos, n. ${ }^{\circ} 1$ (2014), pp. 27-54.

Estrada Saavedra, Marco, “¿Protección a cambio de obediencia? El Leviatán en la lectura de Carl Schmitt”: Estudios Sociológicos, vol. XXI, n. ${ }^{\circ} 62$ (2003), pp. 363-398.

Galli, Carlo, La mirada de Jano, Fondo de Cultura Económica, Buenos Aires, 2011.

Hartmann, Nicolai, Ética, Ediciones Encuentro, Madrid, 2011.

Hinkelammert, Franz. "El concepto de lo político según Carl Schmitt", en Norbert Lechner, Cultura política y democratización, CLACSO-FLACSO-ICI, Santiago de Chile, 1987, pp. 235-251.

McCormick, John, "Fear, Technology and the State: Carl Schmitt, Leo Strauss, and the Revival of Hobbes in Weimar and National Socialist Germany": Political Theory, vol. 22, n. 4 (1994), pp. 619-652.

Mouffe, Chantal, En torno a lo político, Fondo de Cultura Económica, Buenos Aires, 2007.

Schmitt, Carl, "La visibilidad de la Iglesia. Una reflexión escolástica”, trad. Román García Pastor: Daimon. Revista de Filosofia, n. ${ }^{\circ} 13$ (1996), pp. 11-17.

-,El Leviatán en la doctrina del Estado de Thomas Hobbes, Universidad Autónoma Metropolitana, Azcapotzalco, 1997.

-, Catolicismo romano y forma política, Tecnos, Madrid, 2000.

-, El concepto de lo político, en Héctor Orestes Aguilar, Carl Schmitt, teólogo de la política, Fondo de Cultura Económica, México, D.F., 2001, pp. 167-224.

-, Teología política, Trotta, Madrid, 2009.

- La tiranía de los valores, Hydra, Buenos Aires, 2010.

-, El valor del Estado y el significado del individuo, Centro de Estudios Políticos y Constitucionales, Madrid, 2011.

Strauss, Leo y Cropsey, Joseph, Historia de la filosofía política, Fondo de Cultura Económica, México, D.F., 2004. 
Strauss, Leo, "Comentario sobre El concepto de lo politico, de Carl Schmitt", en Heinrich Meier, Carl Schmitt, Leo Strauss y El concepto de lo político. Sobre un diálogo entre ausentes, Katz, Buenos Aires, 2008, pp. 133-168.

-, "Derecho natural y la distinción entre hechos y valores", en Derecho natural e historia, Prometeo, Buenos Aires, 2014, pp. 93-131.

Troeltsch, Ernst, El protestantismo y el mundo moderno, Fondo de Cultura Económica. México, D.F., 1979.

Weber, Max, La ética protestante y el espíritu del capitalismo, Alianza, Madrid, 2011.

Zarka, Yves Charles, "Carl Schmitt, una lectura antimoderna de la modernidad: la triple traición a Hobbes": Eikasia, n. ${ }^{\circ} 45$ (2012), pp. 57-70. 